\title{
Fabrication of bulk heterojunction photovoltaic devices using sublimable rhenium diimine complexes as photosensitizers
}

\author{
Hei Ling Wong ${ }^{1}$, Kai Wing Cheng ${ }^{1}$, Kitty Ka Yan Man ${ }^{1}$, Chung Yin Kwong ${ }^{2}$, Wai Kin Chan ${ }^{1 *}$, \\ Aleksandra B. Djurišić ${ }^{3}$ \\ ${ }^{[1]}$ Department of Chemistry, the University of Hong Kong, Pokfulam Road, Hong Kong \\ ${ }^{[2]}$ Department of Electrical and Electronic Engineering, the University of Hong Kong, Pokfulam \\ Road, Hong Kong \\ ${ }^{[3]}$ Department of Physics, the University of Hong Kong, Pokfulam Road, Hong Kong
}

\begin{abstract}
A series of chlorotricarbonyl rhenium (I) bis(phenylimino)acenaphthene (Re-DIAN-X) complexes were used as the photosensitizers for photovoltaic cells. Unlike other transition-metal-based photovoltaic sensitizers that can only be prepared by solution method, these complexes are sublimable. Compared to other rhenium diimine complexes based on bipyridine or 1,4-diaza-1,3-butadiene ligands, these complexes have lower band gaps, which can be modified easily by changing the structure of the ligand. It allows the preparation of blend of metal complexes in order to broaden the sensitization region in UV-vis absorption spectrum. One of the complexes also shows bipolar charge transport character with relatively high charge carrier mobilities in the order of $10^{-3} \mathrm{~cm}^{2} \mathrm{~V}^{-1} \mathrm{~s}^{-1}$. Multilayer heterojunction and bulk heterojunction devices with fullerene as the electron accepting molecule were prepared. For the bulk heterojunction devices, the fill factor and power conversion efficiency under AM 1.5 simulated solar light illumination were 0.51 and $1.29 \%$, respectively. The effects of changing the Re-DIAN/C 60 film thickness, $R e-D I A N / C_{60}$ ratio and variation of ligand structures in the bulk heterojunction devices were studied. The amount of photosensitizer and electron transport molecules may strongly affect the balance between the photon absorption, exciton formation, dissociation, and charge transport processes. Atomic force microscopic images showed that the complex dispersed evenly with fullerene molecules in solid state.
\end{abstract}

\section{INTRODUCTION}

The use of organic materials to fabricate photovoltaic cells has attracted attention recently because of the promising potentials to new solar cells. ${ }^{1}$ Various photovoltaic cells based on both molecular and polymeric materials have been reported. However, the majority of power conversion efficiencies for organic based photovoltaic devices reported to date is less than $1 \% .^{2}$ One of the major barrier to fabricate efficient organic photovoltaic cells is the insufficient exciton dissociation at low bias. In order to design an efficient organic photovoltaic cell, the efficiency for dissociation of excitons and the charge transport process should be improved. We previously showed that diimine complexes based on $d^{6}$ transition metals could act as the photosensitizers ${ }^{3}$ and charge transport molecules ${ }^{4}$ with bipolar character. These complexes show relatively long-lived excited states with metal-to-ligand charge transfer (MLCT) character. Because of the presence of the heavy metal atom, the spin-orbit coupling could be efficient to favour intersystem crossing. This leads to the formation of long-lived triplet excited states. Therefore, the exciton formed may have a longer lifetime after photoexcitation, and subsequent exciton dissociation process is favored. ${ }^{5} d^{6}$ transition metal complexes can be easily prepared and these can be synthesized with various diimine ligands. Many of these complexes have good thermal and photochemical stability.

*waichan@hkucc.hku.hk; phone 852 2859-8943; fax 852 2857-1586 


\section{RESULTS AND DISCUSSION}

\subsection{Synthesis}

Chlorotricarbonyl rhenium (I) bis(phenylimino)acenaphthene (Re-DIAN-X) complex ${ }^{6}$ was used as the photosensitizer to fabricate photovoltaic cells. Synthesis of Re-DIAN-X is shown in Scheme 1 . $^{7}$

\section{Bis(4-phenylimino)acenaphthene 1a:}

A mixture of acenaphthenequinone $(0.5 \mathrm{~g}, 1 \mathrm{~mole})$, aniline $(1.28 \mathrm{~g}, 5 \mathrm{~mole})$ and anhydrous zinc chloride $(0.75 \mathrm{~g}$, 2 mole) was refluxed at $160^{\circ} \mathrm{C}$. Additional aniline was added when stirring became difficult because of evaporation of aniline. After 4 hours, the mixture was cooled to room temperature and vigorously stirred with diethyl ether. The solid was filtered off. The product was washed with diethyl ether several times and then air-dried. Bis(4phenylimino)acenaphthene zinc chloride was obtained. The solid was added to an aqueous solution of potassium carbonate $(6.25 \mathrm{~g}$ in $6.25 \mathrm{ml}$ water) and the mixture was heated under reflux with vigorous stirring. After 2 hours, the mixture was cooled to room temperature. The solid was filtered off and washed with water several times. The product was recrystallized with ethanol and air-dried.

\section{Bis(methylphenylimino)acenaphthene 1b-h:}

The syntheses of $\mathbf{1 b}$-h were carried out under similar reaction conditions by using different substituted aromatic aniline. The preparation of $\mathbf{1 b}$ is described as general procedure. A mixture of acenaphthenequinone $(0.5 \mathrm{~g}, 1$ mole), p-anisidine $(0.74 \mathrm{~g}, 2.2$ mole) and anhydrous zinc chloride $(0.75 \mathrm{~g}, 2$ mole) was refluxed in 20 ml glacial acetic acid at $145^{\circ} \mathrm{C}$. After 30 minutes, the mixture was cooled to room temperature and filtered off. The product was washed with acetic acid and diethyl ether several times and then air-dried. Bis(methylphenylimino)acenaphthene zinc chloride was obtained. The solid was added to an aqueous solution of potassium carbonate $(6.25 \mathrm{~g}$ in $6.25 \mathrm{ml}$ water) and the mixture was heated under reflux with vigorous stirring. After 2 hours, the mixture was cooled to room temperature. The solid was filtered off and washed with water several times. The product was recrystallized with ethanol and then airdried.

\section{Chlorotricarbonyl rhenium (I) bis(phenylimino)acenaphthene 2a-h:}

The syntheses of Re-DIAN-X (2a-h) were carried out by similar procedures. Ligand (1a-h) $(0.5 \mathrm{~g}, 1 \mathrm{~mole})$ and rhenium pentacarbonyl chloride $(0.46 \mathrm{~g}, 1 \mathrm{~mole})$ in $20 \mathrm{ml}$ toluene were refluxed at $140^{\circ} \mathrm{C}$ under nitrogen atmosphere for overnight. The mixture was cooled to room temperature and filtered off. The solid was washed with toluene and dried in vacuum. These complexes can be conveniently purified by sublimation under high vacuum $\left(280^{\circ} \mathrm{C}\right.$ at $\left.10^{-5} \mathrm{mbar}\right)$.

\subsection{Optical properties}

In order to determine the charge carrier mobility of the complex, a thin film (440 nm) of Re-DIAN sandwiched between ITO and gold electrodes was prepared by vacuum sublimation. The hole and electron carrier mobilities of the complex were studied by the conventional time-of-flight experiment. ${ }^{8}$ A pulsed nitrogen laser $(337 \mathrm{~nm}$, pulse width $=4$ ns) was used as the light source. The transient photocurrent profiles showed typical non-Gaussian charge transport characteristics that were dispersive in nature. The electron and hole carrier mobilities of the complex were determined to be $2.5 \times 10^{-3}$ and $2.3 \times 10^{-3} \mathrm{~cm}^{2} \mathrm{~V}^{-1} \mathrm{~s}^{-1}$, respectively. These results agree to our previous report that rhenium complexes exhibited bipolar charge transport character. ${ }^{4}$ The electron deficient DIAN ligand and the rhenium metal centre may act as hopping sites for electron and hole transport, respectively. 

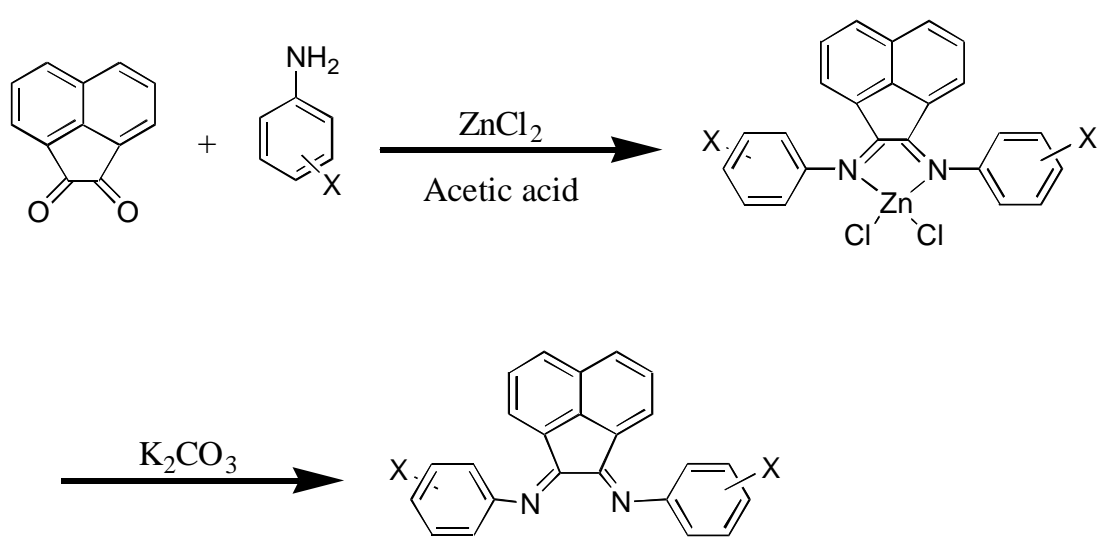

1a-h

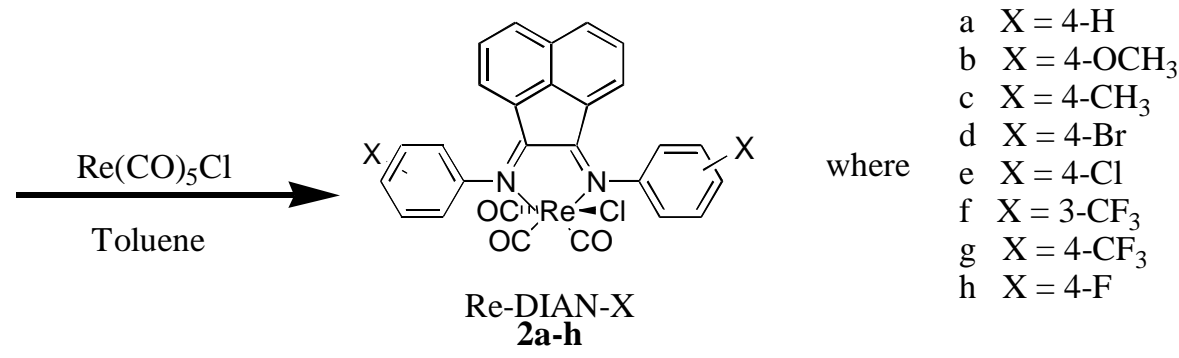

Scheme 1. Synthesis of Re-DIAN-X

\subsection{Photovoltaic properties}

Two types of multilayer photovoltaic devices were fabricated by vacuum sublimation. The first type was multilayer heterojunction device ITO/CuPc/Re-DIAN-X/C $\mathrm{C}_{60} / \mathrm{Al}$ (Type $\mathrm{A}$ device in Table I) in which copper phthalocyanine $(\mathrm{CuPc})$ and fullerene $\left(\mathrm{C}_{60}\right)$ were used as the hole and electron transport molecules, respectively. The second type of device consists of multilayer bulk heterojunction ITO/CuPc/Re-DIAN-X: $\mathrm{C}_{60} / \mathrm{C}_{60} / \mathrm{Al}$ (Type $\mathrm{B}$ device in Table I and Table II) in which Re-DIAN-X and $\mathrm{C}_{60}$ were co-deposited in the same layer (Figure 2). In this type of device, $\mathrm{C}_{60}$ molecules are able to capture electrons more efficiently once excitons are formed. ${ }^{9}$ The thickness of both $\mathrm{CuPc}$ and $\mathrm{C}_{60}$ layers were kept at $10 \mathrm{~nm}$, and the thickness of Re-DIAN-X (or Re-DIAN-X:C 60 mixed layer) was varied from 25 to $100 \mathrm{~nm}$. ITO glass substrate with a sheet resistance of $20 \Omega / \mathrm{sq}$ was used as the anode and aluminium (thickness $=40 \mathrm{~nm}$ ) was used as the cathode. ITO substrates were cleaned by wet cleaning procedure. It consisted of first rubbing with cotton and toluene, cotton and ethanol, and cotton and acetone. Then, they were ultrasonic in deionised water with glass-detergent for 10 minutes, deionised water for 10 minutes, ethanol for 5 minutes, and acetone for 5 minutes consecutively. ITO substrates were rinsed by deionised water before they were immersed into the next solvent in each step. The cleaning steps in ultrasonic bath were repeated until the substrates were clean. The substrates were dried in an oven. UV ozone treatment was carried out for 15 minutes before use. It was found that the ITO surface treatments improve the device performance, mainly by changing the short circuit current. This treatment can remove insulating organic contaminating layer on the ITO surface. The change in the concentration of defects and traps at the interface may enhance the carrier collection efficiency. ${ }^{10}$ 
The current-voltage $(I-V)$ characteristics of different photovoltaic devices under AM 1.5 spectral illumination with power $=100 \mathrm{~mW} / \mathrm{cm}^{2}$ are shown in Figure 1, and their performance data are summarized in Table I and Table II. In the multilayer heterojunction device (Type A device), the open circuit voltage $V_{\mathrm{oc}}$, short circuit current $I_{\mathrm{sc}}$, and fill factor $F F\left[\left(I_{\max } \times V_{\max }\right) /\left(I_{\mathrm{sc}} \times V_{\mathrm{oc}}\right)\right.$, with $I_{\max }$ and $V_{\max }$ corresponding to the point of maximum power output] were measured to be $0.56 \mathrm{~V}, 0.42 \mathrm{~mA} / \mathrm{cm}^{2}$, and 0.32 , respectively (Device 1). The overall conversion efficiency of the power of the incident light into electrical power is given by the $\eta_{\mathrm{p}}$, which is defined as $\eta_{\mathrm{p}}=\left(I_{\mathrm{sc}} V_{\mathrm{oc}} F F\right) / P$, where $P$ is the incident light power. The calculated $\eta_{\mathrm{p}}$ of this device was $0.07 \%$. The relatively poor performance may be due to the limitation of exciton dissociation at the Re-DIAN-X/C 60 junction and the lower absorption by Re-DIAN-X than $\mathrm{C}_{60}$. On the other hand, the photovoltaic performances of multilayer bulk heterojunction devices were greatly improved (Type $\mathrm{B}$ device in Table I and Table II). The $V_{\mathrm{oc}}, I_{\mathrm{sc}}, F F$, and $\eta_{\mathrm{p}}$ of the device with Re-DIAN:C 60 ratio $=1: 1$ (50nm) (Device 6) were 0.51 $\mathrm{V}, 5.07 \mathrm{~mA} / \mathrm{cm}^{2}, 0.51$, and $1.29 \%$, respectively. The simple three-layered Re-DIAN-X sensitized photovoltaic cells show improved performance compared to previously reported $\mathrm{CuPc} / \mathrm{C}_{60}$ heterojunction devices. ${ }^{11}$

Table I. Performance of photovoltaic devices with different Re-DIAN-X derivatives in different conditions. All devices were irradiated with AM1.5 spectral illumination with power $=100 \mathrm{~mW} / \mathrm{cm}^{2}$. The device active area is $0.13 \mathrm{~cm}^{2}$.

\begin{tabular}{cccccccc}
\hline Device & Structure $^{\mathrm{a}}$ & $\mathrm{X}$ & $\begin{array}{c}\text { Thickness of active } \\
\text { layer }(\mathrm{nm})\end{array}$ & $\begin{array}{c}I_{\mathrm{sc}} \\
\left(\mathrm{mA} / \mathrm{cm}^{2}\right)\end{array}$ & $\begin{array}{c}V_{\mathrm{oc}} \\
(\mathrm{V})\end{array}$ & $F F$ & $\eta_{\mathrm{p}}(\%)$ \\
\hline 1 & $\mathrm{~A}$ & $4-\mathrm{H}$ & 25 & 0.42 & 0.56 & 0.32 & 0.07 \\
2 & $\mathrm{~A}$ & $4-\mathrm{Cl}$ & 25 & 0.53 & 0.57 & 0.23 & 0.07 \\
3 & $\mathrm{~A}$ & $3-\mathrm{CF}_{3}$ & 25 & 0.23 & 0.54 & 0.19 & 0.02 \\
4 & $\mathrm{~A}$ & $3-\mathrm{CF}_{3}$ & 40 & 0.01 & 0.57 & 0.17 & 0.001 \\
5 & $\mathrm{~A}$ & $4-\mathrm{F}$ & 40 & 0.01 & 0.61 & 0.15 & 0.001 \\
\hline 6 & $\mathrm{~B}$ & $4-\mathrm{H}_{3}$ & 50 & 5.07 & 0.51 & 0.51 & 1.29 \\
7 & $\mathrm{~B}$ & $4-\mathrm{OCH}_{3}$ & 50 & 3.25 & 0.46 & 0.53 & 0.79 \\
8 & $\mathrm{~B}$ & $4-\mathrm{CH}_{3}$ & 50 & 2.84 & 0.52 & 0.50 & 0.73 \\
9 & $\mathrm{~B}$ & $4-\mathrm{Br}$ & 50 & 2.59 & 0.50 & 0.44 & 0.56 \\
10 & $\mathrm{~B}$ & $4-\mathrm{Cl}_{1}$ & 50 & 3.30 & 0.50 & 0.43 & 0.71 \\
11 & $\mathrm{~B}$ & $3-\mathrm{CF}_{3}$ & 50 & 2.61 & 0.48 & 0.44 & 0.55 \\
12 & $\mathrm{~B}$ & $4-\mathrm{CF}_{3}$ & 50 & 2.71 & 0.44 & 0.54 & 0.64 \\
13 & $\mathrm{~B}$ & $4-\mathrm{F}$ & 50 & 2.75 & 0.47 & 0.48 & 0.62 \\
\hline
\end{tabular}

a Type A device structure: ITO/CuPc(10nm)/Re-DIAN-X(25-40nm)/C $60(10 \mathrm{~nm}) / \mathrm{Al}(40 \mathrm{~nm}), \quad$ Type $\quad \mathrm{B}$ device structure: $\mathrm{ITO} / \mathrm{CuPc}(10 \mathrm{~nm}) / \mathrm{Re}-\mathrm{DIAN}-\mathrm{X}: \mathrm{C}_{60}[1: 1](50 \mathrm{~nm}) / \mathrm{C}_{60}(10 \mathrm{~nm}) / \mathrm{Al}(40 \mathrm{~nm})$

Table II. Performance of photovoltaic devices with different film thickness and ratio of Re-DIAN:C 60 . The device structure is ITO/CuPc $(10 \mathrm{~nm}) / \mathrm{Re}-\mathrm{DIAN}: \mathrm{C}_{60}(25-100 \mathrm{~nm}) / \mathrm{C}_{60}(10 \mathrm{~nm}) / \mathrm{Al}(40 \mathrm{~nm})$. All devices were irradiated with AM1.5 spectral illumination with power $=100 \mathrm{~mW} / \mathrm{cm}^{2}$. The device active area is $0.13 \mathrm{~cm}^{2}$.

\begin{tabular}{ccccccc}
\hline Device & $\begin{array}{c}\text { Thickness of Re-DIAN:C } \\
\text { Codeposition layer }(\mathrm{nm})\end{array}$ & $\begin{array}{c}\text { Ratio of } \\
\text { Re-DIAN: } \mathrm{C}_{60}\end{array}$ & $\begin{array}{c}I_{\mathrm{sc}} \\
\left(\mathrm{mA} / \mathrm{cm}^{2}\right)\end{array}$ & $\begin{array}{c}V_{\mathrm{oc}} \\
(\mathrm{V})\end{array}$ & $F F$ & $\eta_{\mathrm{p}}(\%)$ \\
\hline 14 & 25 & $1: 9$ & 4.13 & 0.37 & 0.49 & 0.74 \\
15 & 50 & $1: 9$ & 2.67 & 0.37 & 0.40 & 0.40 \\
16 & 75 & $1: 9$ & 1.48 & 0.30 & 0.39 & 0.17 \\
17 & 100 & $1: 9$ & 2.29 & 0.30 & 0.46 & 0.31 \\
18 & 25 & $3: 7$ & 4.03 & 0.42 & 0.45 & 0.76 \\
19 & 50 & $3: 7$ & 2.72 & 0.44 & 0.52 & 0.62 \\
20 & 75 & $3: 7$ & 2.93 & 0.46 & 0.43 & 0.58 \\
21 & 100 & $3: 7$ & 0.03 & 0.30 & 0.12 & 0.001 \\
22 & 25 & $1: 1$ & 3.02 & 0.47 & 0.33 & 0.46 \\
23 & 50 & $1: 1$ & 5.07 & 0.51 & 0.51 & 1.29 \\
24 & 75 & $1: 1$ & 4.34 & 0.42 & 0.42 & 0.76 \\
25 & 100 & $1: 1$ & 3.23 & 0.46 & 0.32 & 0.47 \\
\hline
\end{tabular}


Table III. Summary of power conversion efficiency with different film thickness and ratio of Re-DIAN:C $\mathrm{C}_{60}$ in Table II.

\begin{tabular}{cccccc}
\hline \multirow{2}{*}{$\begin{array}{c}\text { Amount of Re-DIAN } \\
\text { in Re-DIAN: } \\
(\%)\end{array}$} & $\begin{array}{c}\text { Ratio of } \\
\text { Re-DIAN: }\end{array}$ & \multicolumn{4}{c}{ Power conversion efficiency (\%) with different } \\
\cline { 3 - 6 } & & \multicolumn{4}{c}{ thickness (nm) } \\
\hline 10 & $1: 9$ & 0.74 & 0.40 & 0.17 & 100 \\
\hline 30 & $3: 7$ & 0.76 & 0.62 & 0.58 & 0.31 \\
50 & $1: 1$ & 0.46 & 1.29 & 0.76 & 0.47 \\
\hline
\end{tabular}

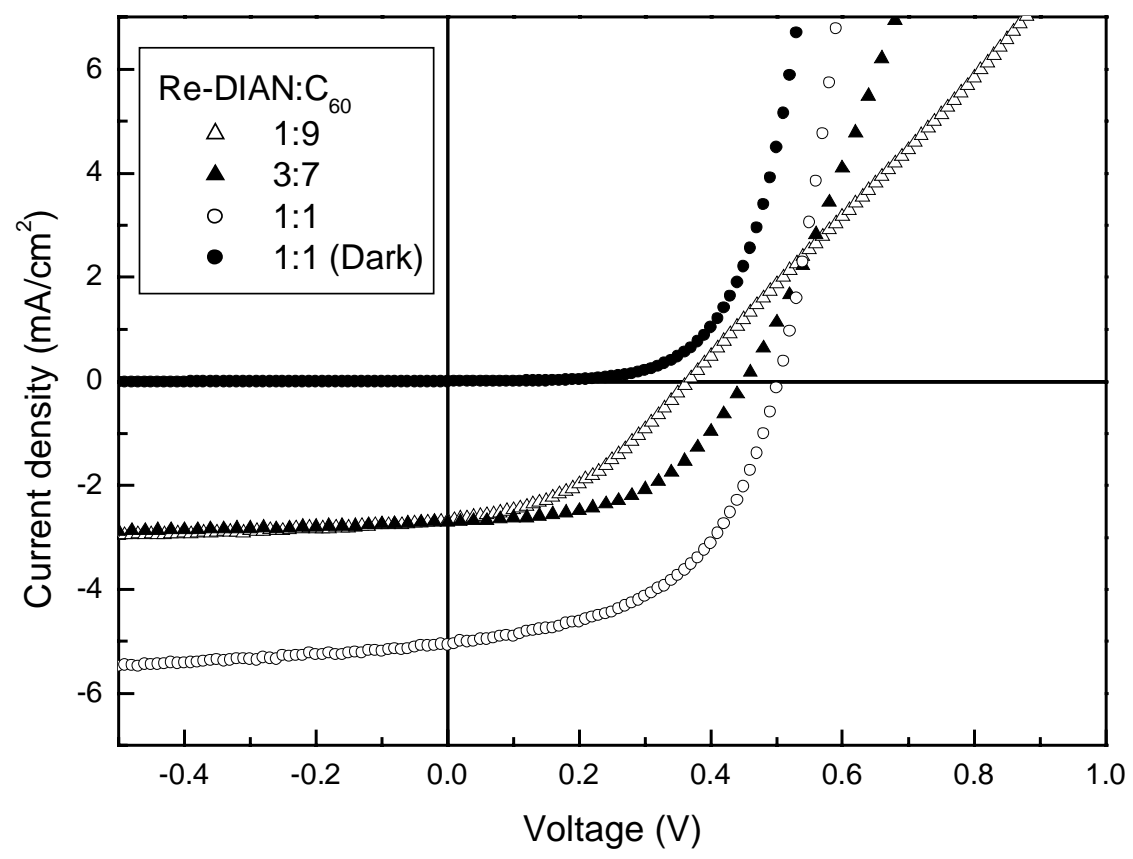

Figure 1. Current-voltage characteristics of photovoltaic devices with different Re-DIAN: $\mathrm{C}_{60}$ ratio in device structure $\mathrm{ITO} / \mathrm{CuPc}(10 \mathrm{~nm}) / \mathrm{Re}-\mathrm{DIAN}: \mathrm{C}_{60}(50 \mathrm{~nm}) / \mathrm{C}_{60}(10 \mathrm{~nm}) / \mathrm{Al}(40 \mathrm{~nm})$ in the dark or under illumination with AM1.5 simulated solar radiation.

The effects of changing the Re-DIAN/C 60 film thickness and Re-DIAN/C 60 ratio are summarized in Table II and Table III. When the Re-DIAN/C 60 ratio was $1: 9$, the highest power conversion efficiency was observed in the device with $25 \mathrm{~nm}$ thickness (Device 14 ). For devices with $\mathrm{Re}-\mathrm{DIAN} / \mathrm{C}_{60}$ ratio $=3: 7$, maximum power conversion efficiency was observed when the thickness was $25 \mathrm{~nm}$ (Device 18). For devices with Re-DIAN/C 60 ratio $=1: 1$, highest power conversion efficiency was observed when the thickness was 50nm (Device 23). These results clearly show that the amount of photosensitizer and electron transport molecules may strongly affect the balance between the photon absorption, exciton formation, dissociation, and charge transport processes. Also, $\mathrm{C}_{60}$ plays an important role in the exciton dissociation process. Although Re-DIAN itself is also a good hole and electron carrier, the electron transport process is still dominated by the $\mathrm{C}_{60}$ molecules, which has an electron carrier mobility of $1.3 \mathrm{~cm}^{2} \mathrm{~V}^{-1} \mathrm{~s}^{-1} .{ }^{12}$ In order to improve devices performance, determining exciton diffusion length and optimising the thickness of each layer should be achieved. 
A series of Re-DIAN-X complexes were used to fabricate photovoltaic cells. The effect of variation of ligand structures in multilayer bulk heterojunction devices was studied (Type B device in Table I). Figure 2 shows the UVvisible absorption spectrum of Re-DIAN-X derivatives in chloroform. These complexes show broad absorption bands that cover most of the visible region in the range between 430 and $600 \mathrm{~nm}$. The maxima absorption peak at around 500 $\mathrm{nm}$ is assigned to be the MLCT $\left[d_{\pi}(\mathrm{Re})\right.$ to $\left.\pi^{*}(\mathrm{DIAN})\right]$ electronic transition. The absorption peaks of complexes with electron-withdrawing groups are red shifted while the absorption peaks of complexes with electron-donating groups are blue shifted in the UV-vis spectrum with respect to the Re-DIAN complex. It was found that electron withdrawing group could stabilize ligand and results in lower band gap. The electron donating groups did not have significant effect on the HOMO energy level. In Table IV, the difference between bandgaps by absorption spectrum is very small. The exciton dissociation in photovoltaic process may not have significant effect in different Re-DIAN-X complexes. Therefore, the power conversion efficiencies of these Re-DIAN-X complexes are very similar (Type B device in Table I).

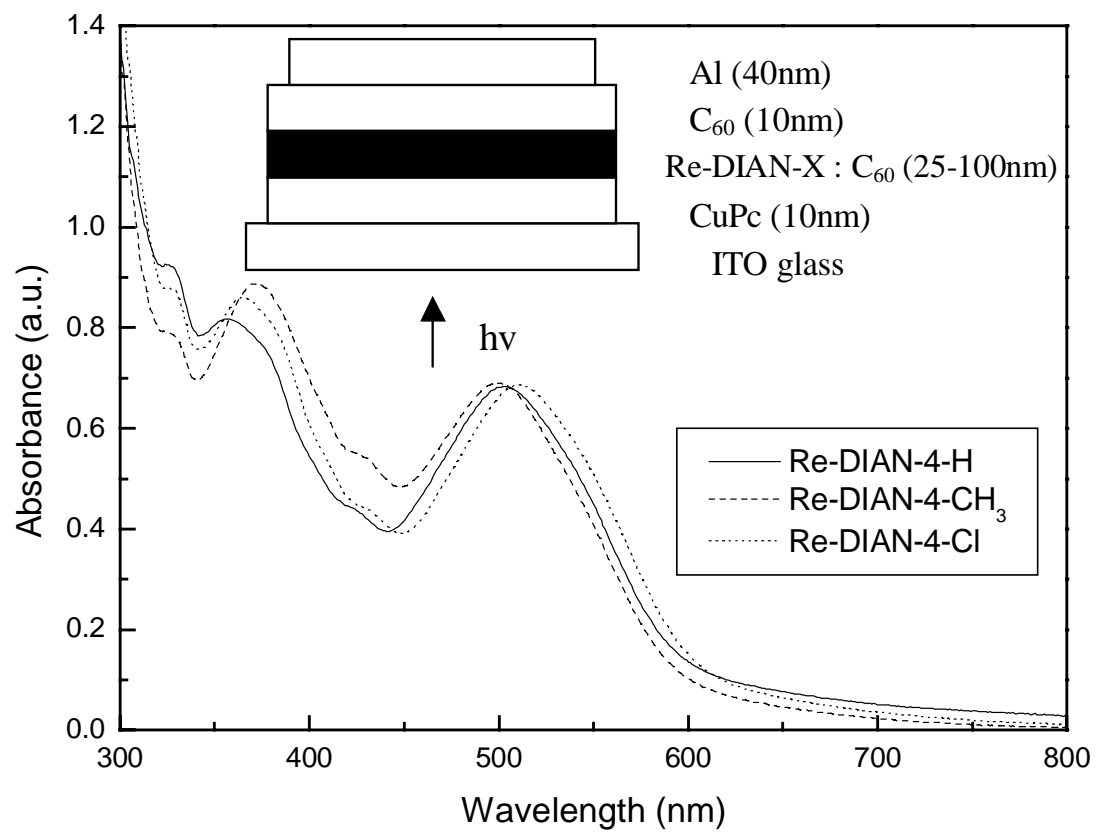

Figure 2. Structure of the three-layer photovoltaic cell and UV-vis absorption spectrum of the Re-DIAN-X complexes in chloroform.

Table IV. Absorption peak position and bandgap of Re-DIAN-X complexes in chloroform.

\begin{tabular}{cccc}
\hline Complex & $\mathrm{X}$ & $\begin{array}{c}\lambda_{\max } \\
(\mathrm{nm})\end{array}$ & $\begin{array}{c}\text { Bandgap by absorption spectrum } \\
{ }^{\mathrm{a}}\end{array}$ \\
\hline $\mathbf{2 a}$ & $4-\mathrm{H}$ & 503 & 2.47 \\
$\mathbf{2 b}$ & $4-\mathrm{OCH}_{3}$ & 493 & 2.52 \\
$\mathbf{2 c}$ & $4-\mathrm{CH}_{3}$ & 500 & 2.48 \\
$\mathbf{2 d}$ & $4-\mathrm{Br}$ & 511 & 2.43 \\
$\mathbf{2 e}$ & $4-\mathrm{Cl}_{2}$ & 509 & 2.44 \\
$\mathbf{2 f}$ & $3-\mathrm{CF}_{3}$ & 518 & 2.40 \\
$\mathbf{2 g}$ & $4-\mathrm{CF}_{3}$ & 516 & 2.41 \\
$\mathbf{2 h}$ & $4-\mathrm{F}$ & 508 & 2.44 \\
\hline
\end{tabular}

a The bandgaps were estimated from absorption spectrum in chloroform. 


\subsection{Tapping mode AFM images}

Efficient charge separation and transport strongly relate to even dispersion of Re-DIAN and $\mathrm{C}_{60}$. Figure 3 shows the tapping mode atomic force microscopy $(\mathrm{AFM})$ images of different Re-DIAN: $\mathrm{C}_{60}$ blends $(50 \mathrm{~nm})$ fabricated on ITO substrates. All samples were prepared by vacuum deposition on unheated substrate. It is expected that there is no significant difference between bulk and surface morphologies. Phase contrast AFM image provides information on the difference in viscoelasticity between materials. It was used to study the miscibility of blends in polymer photovoltaic cells. ${ }^{13-15}$ The thin film with 1:1 ratio [Figure 3(a)] shows approximately $30 \mathrm{~nm}$ features size, and its phase image clearly indicates that the "peaks" are of different chemical nature from the surrounding "valleys". Since the exciton diffusion length in organic materials is typically small, such small feature size would favor exciton separation and subsequently yield higher efficiency. The height and phase images clearly show that smaller aggregations were formed by either one type of molecules compared to other thin films with different Re-DIAN: $\mathrm{C}_{60}$ ratio. These observations suggest that the rhenium complex and fullerene molecules are highly compatible with each other. ${ }^{5}$ For thin films with 1:9 and 9:1 Re-DIAN: $\mathrm{C}_{60}$ ratio, either $\mathrm{C}_{60}$ [Figure 3(b)] or Re-DIAN [Figure 3(c)] constitutes the major component in the thin film, and the aggregates are greater than those in Figure 3(a). However, the roughnesses of these films are relatively small.
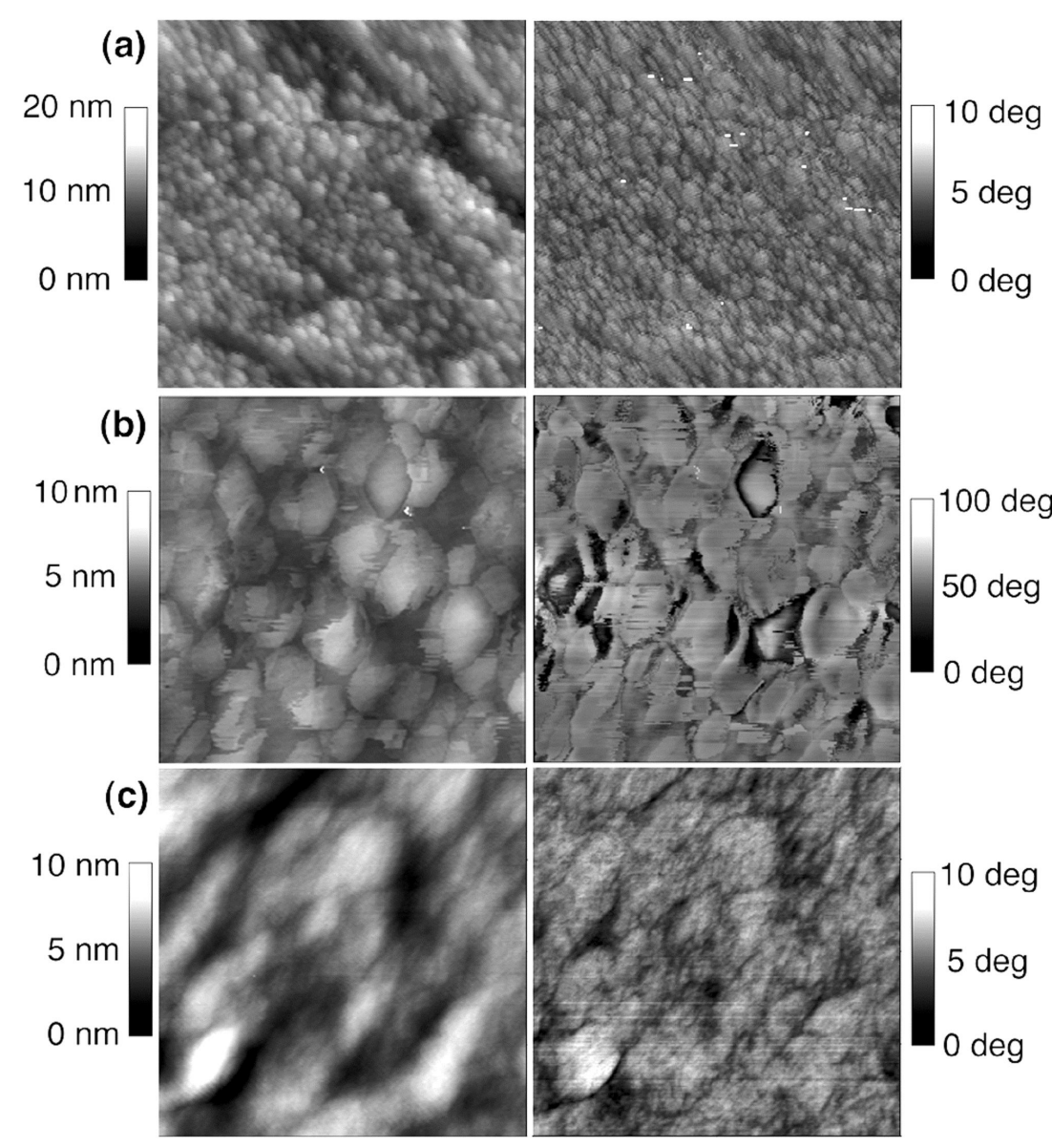

Figure 3. Tapping mode AFM images (left: height; right: phase) of Re-DIAN:C 60 blends with different ratio: (a) Re-DIAN: $\mathrm{C}_{60}=1: 1$; (b) Re-DIAN: $\mathrm{C}_{60}=1: 9 ;$ (c) Re-DIAN: $\mathrm{C}_{60}=9: 1$. The full scale of all images are $1 \mu \mathrm{m} \times 1 \mu \mathrm{m}$. 


\section{CONCLUSION}

A series of chlorotricarbonyl rhenium (I) bis(phenylimino)acenaphthene (Re-DIAN-X) complexes were synthesized. These complexes were used as the photosensitizers to fabricate photovoltaic cells. These complexes have low band gaps and good processibility. One of the complexes also shows bipolar charge transport character with relatively high charge carrier mobilities. Efficient multilayer bulk heterojunction photovoltaic devices with simple structures were fabricated based on rhenium diimine complexes. The active layer consists of a blend of rhenium complex and fullerene that were co-deposited by vacuum sublimation. The fill factor and power conversion efficiency under $\mathrm{AM} 1.5$ simulated solar light illumination were 0.51 and $1.29 \%$, respectively. The effects of changing the ReDIAN/C 60 film thickness, Re-DIAN/C 60 ratio and variation of ligand structures in the bulk heterojunction devices were studied. The amount of photosensitizer and electron transport molecules may strongly affect the balance between the photon absorption, exciton formation, dissociation, and charge transport processes. Atomic force microscopic images showed that the complex dispersed evenly with fullerene molecules in solid state. Improved performance can be achieved by determining exciton diffusion length, optimizing the thickness of each layer and fabrication of more sophisticated devices.

\section{ACKNOWLEDGMENTS}

The work reported in this paper is substantially supported by the Research Grants Council of the Hong Kong Special Administrative Region, China (Project Nos. HKU 7096/00P, 7075/01P, and 7096/02P). Partial financial support from the Committee on Research and Conference Grants (University of Hong Kong) is also acknowledged.

\section{REFERNECES}

1 C. W. Tang, Appl. Phys. Lett. 48, 183, 1986; G. Yu, J. Gao, J. Hummelen, F. Wudl, A. J. Heeger, Science 270, 1789, 1995.

2 P. Peumans, A. Yakimov, S. R. Forrest, J. Appl. Phys. 93, 3693, 2003.

3 W. K. Chan, X. Gong, W. Y. Ng, Appl. Phys. Lett. 71, 2919, 1997; L. S. M. Lam, W. K. Chan, A. B. Djurisic, E. H. Li, Chem. Phys. Lett. 362, 130, 2002.

4 X. Gong, P. K. Ng, W. K. Chan, Appl. Phys. Lett. 75, 3920, 1999.

5 H.L. Wong, L.S.M. Lam, K.W. Cheng, K.Y.K. Man, W.K. Chan, Appl. Phys. Lett. 84, 2557, 2004.

6 G. Knör, M. Leirer, T. E. Keyes, J. G. Vos, A. Vogler, Eur. J. Inorg. Chem. 749, 2000.

7 R.V. Asselt, C.J. Elsevier, W.J.J. Smeets, A.L. Spek, R. Benedix, Recl Trav. Chim. Pays-Bas. 113, 88, 1994.

8 P. M. Borsenberger, J. Appl. Phys. 68, 6263, 1990.

9 P. Peumans, S. R. Forrest, Appl. Phys. Lett. 79, 126, 2001; J. J. M. Halls, K. Pichler, R. H. Friend, S. C. Moratti, A. B. Holmes, Appl. Phys. Lett. 68, 3120, 1996.

10 C.Y. Kwong, A.B. Djurišić, P.C. Chui, L.S.M. Lam, W.K. Chan, Appl. Phys. A.77, 555, 2003.

11 T. Stübinger, W. Brütting, J. Appl. Phys. 90, 3632, 2001.

12 G. Priebe, B. Pietzak, R. Könenkamp, Appl. Phys. Lett. 71, 2160, 1997.

13 M. Granström, L. Petritsch, A. G. Arias, A. Lux, M. R. Andersson, R. H. Friend, Nature 395, $257,1998$.

14 M. G. Nava, S. Setayesh, A. Rameau, P. Masson, J.-F. Nierengarten, New J. Chem. 26, 1584, 2002.

15 S. E. Shaheen, C. J. Brabec, N. S. Sariciftci, F. Padinger, T. Fromherz, J. C. Hummelen, Appl. Phys. Lett. 78, 841, 2001. 